uch conditions has generally been considered extremely serious. I am indebted to Mr. Morgan and to Mr. Lewis, house surgeon, for notes.

Brighton.

\section{A CASE OF KOCHER'S RADICAL MODIFICATION OF THE ALEXANDER ALIQUIÉ OPERATION.}

BY Fref. Edge, M.D. LoNd., F.R.C.S. ENG., M.R.C.P. LOND., B.Sc.,

SURGEON TO THE WOLVERHAMPTON AND DISTRICT HOSPITAL FOR WOMEN.

IN the Archiv für Gynakologie, 1893, is an account by Lanz of Kocher's modification of this operation, with a report of successful cases. The modifications introduced by Kocher are the splitting up of the inguinal canal so as to isolate the round ligament with ease, the drawing upon the round ligaments in the directions of the anterior superior iliac spines, and their fixation upon the aponeuroses of the external oblique muscles whilst being drawn upon. Having a case of prolapse with retroflexion, which was unrelieved by mechanical or medicinal means, I performed Kocher's modified operation as follows (to save the valuable space of The LANCET I shall limit my description to the operation and avoid details) :

Taking the left side first, an incision was made from just above and external to the pubic spine to about three quarters of an inch above and internal to the anterior superior iliac spine, running parallel to Poupart's ligament. The external inguinal ring was felt as a yielding space and seen to be filled with a plug of fatty areolar tissue. A director was passed into the inguinal canal and the anterior wall slit up with a scalpel. The round ligament lay exposed with the branch of the genito-crural nerve. The ligamentwas then picked up with forceps, divided distally, and separated up to the internal inguinal ring. Exactly the same steps were performed on the right side. The second assistant now passed a uterine sound and held the uterus forwards. The two ligaments were then drawn apon in the direction of the iliac spines until firm resistance was felt, and the peritoneum was pulled on each as a knuckle three-quarters of an inch long. These knuckles were separated and pushed back. The round ligaments were stitched upon the oblique aponeuroses with continuous silk sutures whilst the given tension was being maintained, and the inguinal canal was closed as after operation for radical cure of hernia. The skin was then sutured with silkworm gut sutures. What at once strikes the operator is the great possibility of hernia following the operation. Another impression is that the round ligaments are very easy to find and can now be treated in any way required, and a following thought is forced upon one that by methods which do not open the inguinal canal the round ligaments cannot possibly be isolated and drawn ont to the necessary extent. As to the formation of hernia afterwards I cannot yet speak, but it appears to me that if the inguinal canal be stitched with care the danger should be much less than after abdominal section. What, however, more than any other element, is felt by the operator is that he is acting on one of the modern root-principles of surgery, in that he can see everything, and is not working in the dark or trusting in the varying conditions of the round ligaments and their attachments. The after-course of the case was as follows : The patient was perfectly comfortable from the first, and her temperature was never above $99^{\circ} \mathrm{F}$. Although the left incision did not heal at once owing to two stitch abscesses, yet, five weeks after the operation, both incisions were quite soundly healed. The uterus was very elevated, the cervix being only just reachable by the finger per vaginam. I send the account simply to make known the method and to draw attention to its directness and simplicity. Of its value my case will be no test until a year or more has passed.

Wolverhampton.

\section{CASE OF OVARIOTOMY DURING PREGNANCY;} AXIAL-ROTATION CYST.

By W. Travers, M.D. DURh., F.R.C.S. Eng., PHYSICIAN TO THE CHELSEA HOSPITAL FOR WOMEN.

(Reported by E. J. Maclean, M.D., C.M.Edin, Resident Medical Officer.)

THE brief notes which are appended may be read with interest in connexion with Dr. Lewers' cases published in recent number of THE LANCET. ${ }^{1}$ The patient, aged twenty nine, was admitted to the Chelsea Hospital for Women at 2 P.M. on Aug. 23rd, 1893, with the following history. She had been married for eight years and $a$ half and had had six children, the youngest having been born elever months previously. Six years previously she was found ta have an abdominal tumour, which had somewhat obstructed her second confinement, but it did not affect her later ones. At some period during her third pregnancy she was adrisec. by an obstetric physician at a London hospital to have labour brought on prematurely, with the view of the tumour being subsequently removed. This she declined, and the labour was a natural one. She stated that ten days prior to admission she was seized with intense pain in her abdomen, which had continued with more or less severity, Menstruation had not occurred for the past four months. The woman was evidently very ill. The abdomen was generally distended and extremely tender all over, so much so that palpation, to be of any value, was impossible. Vaginal examination showed the uterus to be considerabjy enlarged and pushed against the pubes; the os and cerpix were soft; the fornices distended, evidently by fluid; a thrill was felt generally on percussion; the temperature was $1024^{\circ} \mathrm{F}$; ; the pulse 120 and small. An ovarian tumour with, in every probability, a twisted pedicle was diagnosed, with an equal probability of existing pregnancy. At 6 P.M. the abdomen was opened. The colour of the presenting cyst confirmed the diagnosis. There was general peritonitis. The cyst was covered by recent, soft, and easily swept down adhesions. Eleven pints of dark sanguineons fluid were evacuated. The cyst was right-sided; the nedicle, which was very much thickened from odema and extravasater blood, had to be secured as close to the uterus as possible-it had been twisted two full turns from left to right. An afterexamination of the cyst showed that there had been extensire hæmorrhages into its wall, forming dark livid bosses of considerable size, due to venous congestion and obstructed venons return, and in places suggestive of commencing moist gangrene. The patient bore the operation well; her temperature at 10 P.M. was $99^{\circ}$, and she was fairly comfortable. In the forty-eight hours of the second and third day the thermometer twice recorded $102^{\circ}$; it did not again touch $99^{\circ}$, save in one instance on the tenth day, owing to some suppuration about a stitch. She was discharged well on the twenty-fourth day. She came to the hospital on Dec. 23rd complaining of some slight pain in her right iliac region, but was quite able to get about. Her pregnancy was progressing naturally.

CEREBRAL EMBOLISM OCCURRING IN A GIRL AGED NINE YEARS AND ELEVEN MONTHS.

By Charles Wicks, L.R.C.P., L.R.C.S., L.M. Edin.

Elever months ago a child aged nine years and eleves months came under my care, complaining of præcordial pain, which extended down the left arm. On examination I found a double mitral murmur. Under treatment she greatif improved, and I did not see her again until Dec. 5th, 1893, when she complained of feeling unwell. The mitral murmurs were now markedly developed, and she experienced pain in the left knee, which was distinctly rheumatic. The following day (Dec. 6th) I saw her and found matters slightly improred, but at four o'clock on the same day I was sent for hurriedly and found her suffering from partial aphasia. Althougt conscious she had lost the power of the right side. The temperature was $104.2^{\circ} \mathrm{F}$. and the pulse 120 per minute; the pupils were even and reacting to light; the patellar reflex th very slightly marked, while ankle clonus was very pro nounced; swallowing was quite impossible ; the patient bowels had been opened the same morning, and she now nasse urine involuntarily in bed. Knowing the child, and havi had the opportunity of watching the case thoroughly, $m$ diagnosis of embolus was easily formed and my prognos grave. The temperature gradually rose from $1042^{\circ}$ to 10 and the pulse varied from 120 to 168 . In the evening I calle my friend Dr. T. Harrison Davison to see the case with w and his opinion quite confirmed the diagnosis I had madt The patient passed slowly into profound coma at $8.30 \mathrm{P}$ and died at 1.30 A.M. on Dec. 7th. On obtaining permissio to make a limited post-mortem examination the same day 